Logos Universality Mentality Education Novelty, Section: Social Sciences

ISSN: $2284-5747$ (print), ISSN: $2284-5747$ (electronic)

Covered in: CEEOL, Index Copernicus, Ideas RePEc, EconPapers, Socionet

\title{
INTERNAL CONTROL SYSTEM: COST OF RISK VS. RISK MANAGEMENT. CASE STUDY: ROMANIAN BANKING SYSTEM
}

Florin ANDREI

Logos Universality Mentality Education Novelty, Section:

Social Sciences, IV (1), 133-143

The online version of this article can be found at:

http://lumenjournals.com/social-sciences/

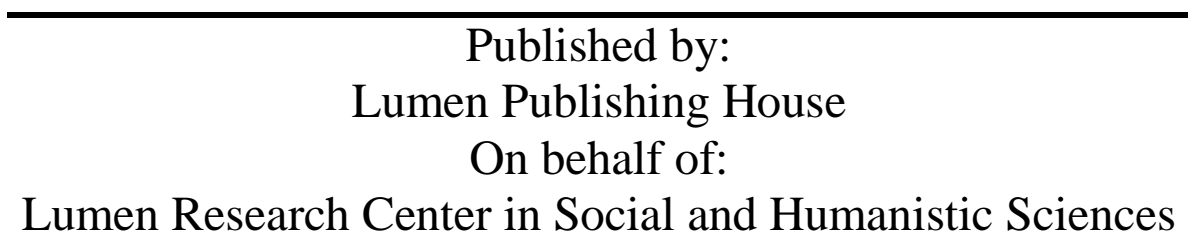




\title{
Internal Control system: Cost of Risk vs. Risk Management. Case study: Romanian Banking System
}

\section{Florin ANDREI ${ }^{1}$}

\begin{abstract}
The evolution of the global financial systems from the last 8-10 years showed to all involved stakeholders (from Supervisory Authorities to shareholders) that a good market discipline is necessary. This statement is derived from the observation period that considered the global economic growth registered in the years 2005-2008 but also taking into consideration the years preceding the global financial crisis.

The scope of the article is to illustrate a brief picture of the internal governance in financial institutions before the financial crisis, as well as the latest developments and guidelines issued in order to enhance the internal governance through its risk management and internal control system. The main objective of the paper is to present and propose a new concept in the internal control system, the three lines of defense model. A case study is made considering a Bank from Top 5 Assets from Romania (Assets bigher than EUR 5 bln.) in order to observe the implementation and execution of the new internal control system. For the current exercise the component of the cost of risk represented by administrative costs of the risk management program was taken into account as to show the costs of the implementation and execution of a strong and reliable internal control system.

The results of the exercise revealed a cost of approximately EUR 0.8 mio per year coming from the salary expenses and also EUR 0.1 mio represented by the cost and implementation of a software which helps in the daily activities of the Credit Riske Control function.

The conclusion of the article underlines the necessity of the financial institutions to strengthen their internal control system considering the regulatory requirements but, also as a driver in order to bave a better and solid risk management program which leads to an improved market and credit discipline.
\end{abstract}

\section{Keywords:}

Cost, risk, management, control, market, discipline.

$1 \mathrm{PhD}$ Student, University Teacher Assistant at Academy of Economic Studies, Romania, fl.andrei@yahoo.com. 


\section{Introduction}

The evolution of the global financial systems from the last 8-10 years showed to all involved stakeholders (from Supervisory Authorities to shareholders) that a good market discipline is necessary. This statement is derived from the observation period that considered the global economic growth registered in the years 2005-2008 but also taking into consideration the years preceding the global financial crisis.

The scope of the article is to illustrate a brief picture of the internal governance in financial institutions before the financial crisis, as well as the latest developments and guidelines issued in order to enhance the internal governance through its risk management and internal control system. The main objective of the paper is to present and propose a new concept in the internal control system, the three lines of defence model.

The article contains a case study considering a Bank from Top 5 Assets from Romania (Assets higher than EUR 5 bln.) in order to observe the implementation and execution of the new internal control system. For the current exercise the component of the cost of risk represented by administrative costs of the risk management program was taken into account as to show the costs of the implementation and execution of a strong and reliable internal control system. Similar analysis related to the cost of risk through the implementation of a internal control system and risk management program were performed by Hulett, D. (2011), „Integrated Cost-Schedule Risk Analysis. England: Gower Publishing Limited” and Priven, M. (2008), „Comparative cost of risk survey. Arizona Dept. of Transportation".

\section{Governance and methodologies}

A definition for the cost of risk could be the one mentioned by the Office of Risk Management, as "the cost of actual losses sustained, administrative costs of the risk management program, costs of funding losses, cost of risk control efforts and other outside service costs"(Office of Risk Management, Risk. Identification, Analysis and Control guidelines, Washington, US, 2015).

From the above mentioned definition, for the purpose of this article, the administrative costs of the risk management program will be considered. In this case the case study will focus on the expenses 
generated by the cost of staff and consultancy for the implementation of a proper internal control system.

When speaking about the internal control system we should have in mind also the internal governance framework applicable in the financial institutions. The internal governance is defined and requested according to the article 22 of the Directive 2006/48/EC which states that "every credit institution has robust governance arrangements, which include a clear organisational structure with well defined, transparent and consistent lines of responsibility, effective processes to identify, manage, monitor and report the risks it is or might be exposed to, adequate internal control mechanisms, including sound administrative and accounting procedures, and remuneration policies and practices that are consistent with and promote sound and effective risk management" (Article 22 of the Directive 2006/48/EC of the European Parliament and of the Council of 14 June 2006 relating to the taking up and pursuit of the business of credit institutions, Bruxelles, June 14th, 2006.).

Within the international governance standards a new concept was introduced, 'Know your structure' which refers to the aim of a better understanding of the organization. Also, the term is written as to assure a better identification of the complexity of the organisation activities.

The importance of the internal governance is given mainly by the fact that this is a key element of good performance for a financial institution and a well-functioning banking system. Thus, the trust and the reliability in the banking system play a key role in the proper functioning of the economy.

After the September 15th, 2008 moment (Lehman Brothers collapse), which marked the beginning of the financial crisis, all the banking supervisors reacted and started to issue new guidelines and principles for an efficient and effective internal corporate governance (for example the following guideline was published: Banking Committee for Banking Supervision: „Principles for enhancing corporate governance", Basel, October 4th, 2010). The main purpose was to correct the weakness identified leading to a superficial or inefficient internal governance system. These deficiencies, even if were not considered the cause of the financial crisis, were closely associated with it. 
In line with the conclusion mentioned in the paper issued by European Banking Authority, "the risk management and the internal control frameworks were often not sufficiently integrated within institutions or groups. A uniform methodology and terminology was missing, so that a holistic view of all risks did not exist. Control functions often lacked appropriate resources, status and/or expertise". ( Article 21 of the EBA Guidelines on Internal Governance, GL 44, London, September 27th, 2011).

Thus, EBA identified that the Management Bodies of the financial institutions did not had a complete understanding and view of all risks that the organization was exposed to. Also, it is to be mentioned that the control functions (mainly 2nd level control) were even in the early stage of development (corresponding also to a lack of experience) or were completely missing.

According to the above mentioned guideline, "Internal governance includes all standards and principles concerned with setting an institution's objectives, strategies, and risk tolerance/appetite; how its business is organised; how responsibilities and authority are allocated; how reporting lines are set up and what information they convey; and how internal control is organised. Internal governance also encompasses sound IT systems, outsourcing arrangements and business continuity management". (Article 30, Section 2, of the EBA Guidelines on Internal Governance, GL 44, London, September 27th, 2011)

The Governance Structures are defined in accordance with the organizational chart of the institution having a unitary or a dual Board system. In the unitary Board system the management and supervisory functions are exercised by the same structure while in the dual Board system the two functions are separated.

Each internal governance structure contains an internal control system, usually organized within the three-lines-of-defence model.

Considering the definition released by the EBA, "the internal control framework of an institution should ensure effective and efficient operations, adequate control of risks, prudent conduct of business, reliability of financial and non-financial information reported, both internally and externally, and compliance with laws, regulations, supervisory requirements and the institutions internal rules and decisions. The internal control framework should cover the whole organisation, including the activities of all business, support and control 
units." (Article 24, Para. 2, Section 3, Title 2, of the EBA Guidelines on Internal Governance, GL 44, London, September 27th, 2011)

Thus, an integrated internal control system should be well documented, transposed in a clear way and made available to all implied parties. The three lines of defence model is established considering the segregation between the control functions. A definition given by the Institute of Internal Auditors states that "the Three Lines of Defence model provides a simple and effective way to enhance communications on risk management and control by clarifying essential roles and duties. It provides a fresh look at operations, helping to assure the ongoing success of risk management initiatives, and it is appropriate for any organization - regardless of size or complexity. (Institute of Internal Auditors, Position Paper issued on January 2013, Global Headquarters 247 Maitland Avenue Altamonte Springs, Florida 32701 USA.)"

Considering the above mentioned definition, the following control functions were identified:

- first line of control is usually represented by the business and support units from an institution (e.g. Branches from a Bank, Operations functions from a Bank that acts to support the Branch personnel in the daily activities);

When speaking about internal controls in business or support units we must have in mind the principle of " 4 eyes" applied when performing any tasks and activities. After the financial crisis started a lot of financial institutions concentrated on the establishment of the internal controls in each area of work.

- second line of control is represented by the control functions established within an institution. Such functions are represented by Risk Control function, Security function, Compliance function, Risk Management, Financial Control and Quality;

The Risk Control function is responsible with identifying the risks and designing and implementing mitigation actions. The function is also responsible with monitoring and reporting the relevant risk limits and overall risk appetite. Generally such functions did not exist in the financial institutions before 2009 which is the case also for the example given in this article.

The Risk Management function is generally responsible with the design and implementation of the risk strategies and policies. Also, in some financial institutions, the function is responsible also with the 
monitoring of the overall risk appetite. Usually the Risk Management function comprises the management of the main risks such as: credit, market and operational.

Compliance function has the primary responsibility to manage the compliance risk that the financial institutions are exposed to. Thus, the Compliance function should ensure that the institution is respecting all the laws and regulations and also it must advise the Management in relation to any requirements that an institution should meet and evaluate the possible impact. The access to Management Bodies is ensured for Compliance function in order to report any misconduct in relation to the internal or external regulation framework that the institution should meet.

All the new products and internal regulations are verified by the Compliance function, any non-compliance aspect being underlined and mitigated.

Compliance function is also performing different types of controls (on site or off site) in order to test how the institution is compliant with the regulations in force (internal and external). Mitigation actions are proposed and implemented as to ensure that the framework is respected.

Security function has the main responsibility to mitigate the risk related to continuity management, physical security as well as fraud risk.

- third line of defence is represented by Internal Audit function which has the role to verify all the other control functions and to give assurance over the internal control system in place. Thus the internal control system should be both, effective and efficient.

The main responsibility of the Internal Audit function is to evaluate if the institution through the units and processes (including also second level control function) are compliant with the policies and procedures in place.

The principal reporting line of the Internal Audit function is directly ensured to Management Bodies and also to the audit Committee. All findings and recommendations are presented and are included in the follow-up process in order to ensure the proper implementation.

The three lines of defense model can be summarized as follows (Adapted from Institute of Internal Auditors, Position Paper issued on January 
2013, Global Headquarters 247 Maitland Avenue Altamonte Springs, Florida 32701 USA.):

Fig. 1 Internal Control System based on the Three Lines of Defense Model

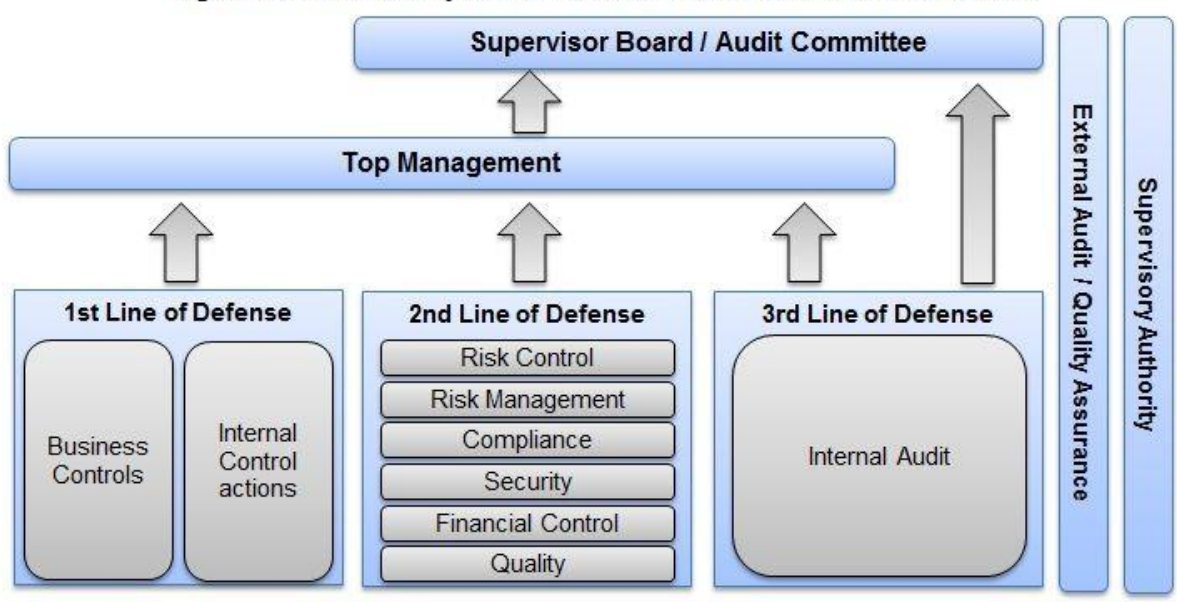

The interaction of the second and third level control functions with the Management of the institution is ensured through different reporting lines. The control functions should inform the Management bodies about any deficiencies identified related to the internal control system and also about the causes and the risks incurred also including, if the case, a dedicated analysis. Recommendations and follow-up actions should also be taken into consideration for the deficiencies presented.

\section{Costs and benefits of the Internal Control System}

The implementation of the new guidelines and recommendations related to the three-lines of defense model does not incur direct costs for the financial institutions with a direct impact in the P\&L.

The indirect costs will be represented by the staff costs, anyhow depending of the institutions profile and complexity. The costs will be represented by additional staff that must be hired and the incentives that should be paid. Also, costs related to the training of the staff and possible implementation of the IT solutions should be considered.

The main benefit of the financial institutions is represented by a strong and improved internal control system leading to a better 
mitigation of the risks to which the institution is exposed. Thus, will trigger lower losses coming from an inadequate management of the main risks, in particular credit and operational ones.

Considering the change in costs related to staff, another point of attention should be raised over the National Supervisors (relevant for the countries that are not in the Eurozone) and European Central Bank. New experts had to be hired in order to implement and disseminate the newly introduced requirements and also in order to monitor the risk profile of the financial institutions supervised.

Case study: Analyze over the implementation of the internal control system in Romanian Banking System

In the following lines it is presented an analysis made in a Romanian Bank from Top 5 (considering the asset volumes). The main focus is to assess the impact over the costs (and indirect in the P\&L) of the implementation of the three lines of defense model. The costs relate to the incentives paid to the newly hired employees and, where applicable, the cost of software implemented.

The assessment will take into account the newly hired employees from the second line of the internal control system and the IT tools implemented. Below is a table which summarizes the personnel costs for the selected period.

Table 1. Personnel costs.

\begin{tabular}{|l|l|l|}
\hline Department & $\begin{array}{l}\text { Staff at December } \\
31^{\text {st }}, 2008\left(\mathrm{~S}_{2008}\right)\end{array}$ & $\begin{array}{l}\text { Staff at December } \\
31^{\text {st }}, 2014\left(\mathrm{~S}_{2014}\right)\end{array}$ \\
\hline $\begin{array}{l}\text { Compliance (second level } \\
\text { control) }\end{array}$ & 2 & 10 \\
\hline Credit Risk Internal Control & 0 & 5 \\
\hline Credit Risk Management & 12 & 25 \\
\hline Security (including Anti-Fraud) & 0 & 9 \\
\hline Operational Risk Management & 3 & 5 \\
\hline Market Risk Management & 3 & 4 \\
\hline Total & 20 & 58 \\
\hline
\end{tabular}

$\mathrm{NE}=\mathrm{S} 2014-\mathrm{S} 2008=38$, where NE represents the new employees in the second line of control functions 
Considering that the Bank analyzed has approximately 3,000 employees, the newly hired specialists represents only about $1.2 \%$ out of the total personnel.

In order to make a cost related calculation, the average salary from Risk Management area was used, approximately EUR 1,780 (gross salary, including also all related taxes paid by the Bank in respect to the local legislation).

AS $=1,780$ EUR, where AS is the average gross salary

$\mathrm{NSC}=$ AS X NE $=1,780$ X $38=67,640$ EUR, where NSC is the cost with new staff hired (monthly base)

NSCA $=$ NSC X $12=811,680$ EUR, where NSCA is the annual cost with the new staff hired

From the above calculation we can observe that the total cost of implementing an internal control system based on three lines of defense can reach the amount of 0.8 mio EUR.

Also, it is to be considered the implementation of a software product that will help the Compliance Function, the total amount for the implementation being EUR 50,000.

In this case:

CICS $=$ NSCA + CS $=811,680+50,000=865,680$ EUR, where

CICS - cost of implementation for the internal control system

CS - cost of software product

\section{Conclusion}

The recent global financial crisis offers a very good image of the financial systems risk management programs implemented through the governance processes and procedures.

The analysis performed measure the administrative costs implications related to the implementation of an improved model for then internal control system based on the three pillars. It is assumed a better segregation of responsibilities and also an improved risk management program.

The statements made in the paper have practical and economic implications. In practice, the three lines of defence model presented can be applied by any financial institution in order to have a sound and reliable risk management program. 


\section{Acknowledgement:}

This work was co-financed from the European Social Fund through Sectoral Operational Programme Human Resources Development 2007-2013, project number POSDRU/159/1.5/S/134197 „Performance and excellence in doctoral and postdoctoral research in Romanian economics science domain"

\section{References}

Hulett, D. (2011). Integrated Cost-Schedule Risk Analysis. England: Gower Publishing Limited.

Priven, M. (2008). Comparative cost of risk survey. Arizona Dept. of Transportation.

*(2015). Risk Identification, Analysis and Control guidelines. Washington, USA.

*(2006). Directive 2006/48/EC of the European Parliament and of the Council of 14 June 2006 relating to the taking up and pursuit of the business of credit institutions. Bruxelles.

*(2011). European Banking Authority Guidelines on Internal Governance. London, UK.

*(2013). Institute of Internal Auditors Position Paper. Florida, USA.

\section{Biodata}

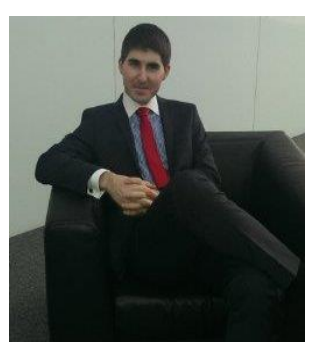

$\mathrm{PhD}$ Student in the final year and University Teacher Assistant at the Academy of Economic Studies, Bucharest Romania. Teaching subjects like Money, Credit Institutions and Financial Analysis within the Department of Money and Banking from the Faculty of Finance, Insurance, Banks and Stock Exchange.

International conferences attended: From Economic Crisis Towards Economic Growth: Fiscal and Monetary Policy Instruments, INFERCEFIMO, 9/26/2013, Bucharest, Romania; Globalization, Intercultural Dialogue and National Identity (GIDNI - I), GIDNI - I, 5/29/2014, Tirgu Mures, Romania; Monetary, Banking and Financial Issues in Central and Eastern EU member countries, MBF-EU, 4/10/2014, Iasi,

Andrei, F. (2015). Internal Control system: Cost of Risk vs. Risk Management. Case study: Romanian Banking System. Logos Universality Mentality Education Novelty, Section: Social Sciences, IV (1), 133-143. 
Romania; LUMEN Rethinking Social Action. Core Values, Iasi, Romania; Managing Sustainable Growth, Portoroz, Slovenia.

Domains of Interest: Risk Management, Credit Risk, Internal Control system, Cost of Risk, Basel II \& III, Internal Audit, Macroeconomic variables.

Professional experience: 4 years in Risk Management and 4 years in Internal Audit in Romanian Banking sector.

Andrei, F. (2015). Internal Control system: Cost of Risk vs. Risk Management. Case study: Romanian Banking System. Logos Universality Mentality Education Novelty, Section: Social Sciences, IV (1), 133-143. 